\title{
Association of body mass index and gender with sleep quality in medical students: A Survey.
}

1. MBBS, DCN, MCPS, M.Phil

Assistant Professor Physiology

Baqai Medical University Karachi.

2. MBBS, FCPS (Hematology)

Professor Pathology

Karachi Medical and Dental College Karachi.

3. MBBS, MCPS

Assistant Professor Community Medicine

Karachi Medical and Dental College Karachi.

4. Final Year Medical Student

Karachi Medical and Dental College Karachi.

5. MBBS, FCPS (Psychiatry)

Professor of Psychiatry

Karachi Medical and Dental College Karachi.

6. Final Year Medical Student

Karachi Medical and Dental College Karachi.

Correspondence Address:

Dr. Saleem Ullah Abro

Department of Physiology

Baqai Medical University Karachi.

saleemullahabro41@gmail.com

Article received on:

13/04/2020

Accepted for publication:

$18 / 06 / 2020$

\section{INTRODUCTION}

College life or student life is considered as the most strenuous yet valuable stage of human life, and medicine or medical sciences is deemed to be the toughest among all disciplines or professions. College life or student life is time duration of change, in which students have autonomy and freedom first time from direct supervision of family members or family and have academic or social pressures with erratic or busy schedules of studies. Major change occurs in the student's life such as dietary problems, intake of drinks and disturbed sleep. These factors would be detrimental to the health or wellbeing of medical students. ${ }^{1}$ Sleep is a physiological complex process for restoration of well-being or health and it is defined as a state of unconsciousness from which a person can be aroused. ${ }^{2}$ Sleep plays a vital role in the homeostasis of the human body, in which it acts as a buffer or first line defense against stress and illness or ill-health. ${ }^{3}$ There is no upper limit to getting maximum sleep. However, it has been stated that obtaining around 7 or 8 hours of sleep per day for adults is essential for optimum health and well-being. ${ }^{4,5}$ Enough data has been collected and compiled on the endless benefits of getting adequate sleep each night. And yet, a poor sleep pattern is observed in both teenagers or adolescents and adults alike. Speaking of the medical students population, getting suboptimal sleep and pulling all-nighters is now a cultural norm owing to the academic burden, social lifestyle or social Medias, alcohol or caffeine intake, and central nervous system (CNS) stimulants, which prevent students from achieving sufficient sleep. ${ }^{6}$ Sleep quality is defined as a measure of the feeling wellbeing, that the human body would be an energetic, active and ready for daily activities of life. Sleep quality is characterized by qualitatively (depth and feeling of restfulness upon awakening) and quantitatively (sleep duration, sleep latency, and 
number of arousal). ${ }^{7}$

Sleep quality is described as good sleep and poor sleep, so good sleep includes not only absence of sleep disturbances like restless leg syndrome or insomnia (difficulty in falling sleep or stay asleep) or obstructive sleep apnea but all the presence of conditions which facilitates the adequate duration of sleep or fall asleep on going to bed or maintenance of sleep continuity without disturbances and after awakening feel refreshed or active ${ }^{8}$, while Poor sleep quality have a serious health issues most likely i-e physical, mental and psychological as well as poor performance during class work or daily day time activities, and risk factors for development of high blood pressure (HTN), increased body mass index (BMI) that ultimately affects the quality of life (QOL).9,10 Moreover, association or relationship between poor sleep and high body mass index or obesity, may vary according to the gender and race. ${ }^{11}$ Overall, estimates of poor sleeping quality (sleeping disturbances/periodic or frequent sleeping problems or excessive sleepiness in daytime) were ranging between $13.8 \%$ and $68.6 \%$ among college students, that depends upon the protocol used for measurement. ${ }^{12,13}$ Sleep quality is assessed subjectively by Pittsburg Sleep Quality Index (PSQI). ${ }^{14}$ It has been observed usually or regularly that in the first few hours of morning in the class, the alertness level of students greatly reduced or decreased due to inadequate sleep or disturbed sleep, which subsequently has an impact on the academic performance and health. However, not enough literature is found in relation to medical students in Pakistan, considering the importance of a sound mind and healthy body in the field of medical profession. Our aim was to assess the association of body mass index and gender with sleep quality in medical students: a survey.

\section{MATERIAL \& METHODS}

This descriptive cross-sectional survey was conducted in Dow University of health sciences (DUHS), Jinnah Sindh medical university (JSMU), and Karachi medical and dental college (KMDC) of Karachi by Non probability, convenience sampling technique. Duration of study was two months from $1^{\text {st }}$ January to $31^{\text {st }}$ March 2019 and having age of 18 to 24 years. Considering a population of 3800 students from the above mentioned medical institutes, the sample size calculated by Raosoft is figured to be 350 with alpha level $5 \%$ and confidence level $95 \%$. All the medical students-from first year to fourth year- willing to participate of the above mentioned medical institutes were enrolled in the study. Students having history of intake of drugs (hypnotics or sedatives), history of insomnia, anorexia nervosa and metabolic disorders will be excluded from study. Approval of research was taken from the Ethical review board (ERB), Karachi medical and dental college (KMDC) of Karachi and Informed consent was taken from the enrolled students, after expressing the purpose and procedure of the study. Proformas for data collections were signed by the students, and samples of participants or consent of students were taken in accordance with the Declaration of Helsinki. ${ }^{15}$

Demographic information of students were taken, such as age, gender, and body weight $(\mathrm{Kg})$ and height $\left(\mathrm{m}^{2}\right)$. Body mass index (BMI) was calculated as weight divided by height $(\mathrm{kg} /$ $\mathrm{m}^{2}$ ). It was categorized on bases of international classification into underweight (BMI $\leq 18.5)$, normal weight (BMI < 25), overweight (BMI between 25 and 30) and obesity (BMI $\geq 30) .{ }^{16}$ Sleep quality of students were assessed by the Pittsburgh Sleep Quality Index (PSQI) scale for the previous month and differentiate among normal and poor sleepers. This index has a validity, reliability and high levels of subjective consistency.

The Pittsburgh Sleep Quality Index (PSQI) is subjective questionnaire consisting of 19 items with seven components likely subjective sleep quality; sleep latency; sleep duration; habitual sleep efficiency; sleep disturbances; use of sleep medication; and daytime dysfunction. This subjective questionnaire consists of 19 items, which is coded on scale i-e 0-3 and zero (none) to three (three times of week). The sum of all scores expresses the score of sleep quality in between the range of 0-21, with higher scores expresses the poor or lower sleep quality or insomnia. 
So that these included students were divided as good (scores <5) and poor or insomnia (scores $>5$ ) sleep quality. ${ }^{14}$ Descriptive statistics were analyzed as frequency, percentage (\%), and mean \pm standard deviation. One way ANOVA was used for comparison of Pittsburgh Sleep Quality Index (PSQI) scores with respect to institute.

The Pearson Chi Square test was used for obtaining the association between sleep quality poor sleep and Good sleep with gender and body mass index. The questionnaire and collected data were double checked and entered in computer for analysis. Data was analyzed by using statistical software package system (SPSS) version 22.0. The $p<0.05$ was considered as a statistical significant in study.

\section{RESULTS}

Descriptive statistics of quantitative variables like mean age of participants was $20.83 \pm 1.54$ years, mean weight was $55.78 \pm 10.81 \mathrm{~kg}$, mean height was $1.90 \pm 0.11$ meters, mean Body mass index (BMI) was $15.53 \pm 3.5 \mathrm{~kg} / \mathrm{m} 2$, and the mean PSQI score of studied samples was $10.74 \pm 4.03$ (Table-I). According to gender based comparison of demographic values of study participants, in which mean values of weight in male (69.48 \pm 12.365$)$ and female (53.32 \pm 8.444$)$, mean values of body mass index (BMI) in male (19.2215 \pm 4.20181$)$ and female $(14.8783 \pm 2.92753)$ and mean values of PSQI in male $(9.1379 \pm 4.13139)$ and female $(11.0340 \pm 3.95353)$ showed statistically significant $(p<0.05)$ differences, while values Age and Height showed statistically non-significant $(p>0.05)$ differences (Table-II). The baseline characteristics of studied samples were 382, of which $30.9 \%$ belonged to DUHS, $23.8 \%$ belonged to JSMU while the remaining $45.3 \%$ were from KMDC. Data was gathered from medical student of either sex (84.8\% female while $15.2 \%$ male respectively). Students from different classes of the medical colleges participated (25.1\% belonged to $1^{\text {st }}$ year, $19.1 \%$ were from $2^{\text {nd }}$ year, $29.8 \%$ third year while the $4^{\text {th }}$ year participants were $25.9 \%$ ). The Body mass index (BMI) of study participants were underweight $(79.6 \%)$, normal (16.8\%) and Overweight/obese (3.7\%). According to Pittsburgh Sleep Quality Index (PSQI) scale,
96.3\% had poor sleep (insomnia) and 3.7\% had good sleep (Table-III). Gender based comparison was significantly associated with Sleep Quality $(p<0.05)$, while different categories of body mass index were not significantly $(p>0.05)$ associated with sleep quality in medical students (Table-IV).

\begin{tabular}{|l|c|c|}
\hline \multicolumn{1}{|c|}{ Characteristics } & Mean \pm & SD \\
\hline Age (years) & $20.83 \pm$ & 1.54 \\
\hline BMI $(\mathrm{kg} / \mathrm{m} 2)$ & $15.53 \pm$ & 3.5 \\
\hline Weight $(\mathrm{kg})$ & $55.78 \pm$ & 10.81 \\
\hline Height $(\mathrm{m})$ & $1.90 \pm$ & 0.11 \\
\hline Sleep Quality (PSQI) & $10.74 \pm$ & 4.03 \\
\hline
\end{tabular}

Table-I. Descriptive statistics of quantitative variables.

\begin{tabular}{|c|c|c|c|c|}
\hline & Gender & $\mathbf{N}$ & $\begin{array}{l}\text { Mean } \pm \text { S. } \\
\text { Deviation }\end{array}$ & P-Value \\
\hline \multirow{2}{*}{$\begin{array}{l}\text { Age } \\
\text { (years) }\end{array}$} & Male & 58 & $20.71 \pm 1.545$ & \multirow{2}{*}{0.52} \\
\hline & Female & 324 & $20.85 \pm 1.543$ & \\
\hline \multirow{2}{*}{$\begin{array}{l}\text { Weight } \\
\text { (kg) }\end{array}$} & Male & 58 & $69.48 \pm 12.365$ & \multirow{2}{*}{$0.000^{*}$} \\
\hline & Female & 324 & $53.32 \pm 8.444$ & \\
\hline \multirow{2}{*}{$\begin{array}{l}\text { Height } \\
\text { (m) }\end{array}$} & Male & 58 & $1.9107 \pm .10047$ & \multirow{2}{*}{0.625} \\
\hline & Female & 324 & $1.9027 \pm .11664$ & \\
\hline \multirow{2}{*}{$\begin{array}{l}\text { BMl } \\
(\mathrm{kg} / \mathrm{m} 2)\end{array}$} & Male & 58 & $19.2215 \pm 4.20181$ & \multirow{2}{*}{0.000} \\
\hline & Female & 324 & $14.8783 \pm 2.92753$ & \\
\hline \multirow{2}{*}{$\begin{array}{l}\text { PSQI } \\
\text { Score }\end{array}$} & Male & 58 & $9.1379 \pm 4.13139$ & \multirow{2}{*}{0.001} \\
\hline & Female & 324 & $11.0340 \pm 3.95353$ & \\
\hline
\end{tabular}

Table-II. Gender based comparison of demographic parameters of the participants.

\begin{tabular}{|c|c|c|c|}
\hline \multicolumn{2}{|c|}{ Characteristics } & $n=382$ & $\%$ \\
\hline \multirow{3}{*}{$\begin{array}{l}\text { Name of } \\
\text { institute }\end{array}$} & DUHS & 118 & $30.9 \%$ \\
\hline & JSMU & 91 & $23.8 \%$ \\
\hline & KM\&DC & 173 & $45.3 \%$ \\
\hline \multirow{2}{*}{ Gender } & Male & 58 & $15.2 \%$ \\
\hline & Female & 324 & $84.8 \%$ \\
\hline \multirow{4}{*}{$\begin{array}{l}\text { Year of } \\
\text { Study }\end{array}$} & $1^{\text {st }}$ year & 96 & $25.1 \%$ \\
\hline & $2^{\text {nd }}$ year & 73 & $19.1 \%$ \\
\hline & $3^{\text {rd }}$ year & 99 & $25.9 \%$ \\
\hline & $4^{\text {th }}$ year & 114 & $29.8 \%$ \\
\hline \multirow{3}{*}{ BMI } & Underweight & 304 & $79.6 \%$ \\
\hline & Normal & 64 & $16.8 \%$ \\
\hline & Overweight/obese & 14 & $3.7 \%$ \\
\hline \multirow{2}{*}{$\begin{array}{l}\text { Sleep } \\
\text { Quality }\end{array}$} & poor sleep or insomnia & 368 & $96.3 \%$ \\
\hline & Good Sleep & 14 & $3.7 \%$ \\
\hline
\end{tabular}

Table-III. Baseline characteristics of studied samples $(n=382)$. 


\begin{tabular}{|c|c|c|c|c|c|c|}
\hline \multirow{3}{*}{\multicolumn{2}{|c|}{ Characteristics }} & \multicolumn{4}{|c|}{ Sleep Quality (PSQI Score) } & \multirow{3}{*}{ P-Value } \\
\hline & & \multicolumn{2}{|c|}{ poor sleep or insomnia } & \multicolumn{2}{|c|}{ Good Sleep } & \\
\hline & & $\mathbf{N}$ & $\%$ & $\mathbf{N}$ & $\%$ & \\
\hline Gender & Female & 315 & $85.6 \%$ & 9 & $64.3 \%$ & $0.02^{*}$ \\
\hline \multirow{2}{*}{$\begin{array}{l}\text { Body mass index } \\
\text { (BMI) }\end{array}$} & Underweight & 293 & $79.6 \%$ & 11 & $78.6 \%$ & \multirow{2}{*}{0.76} \\
\hline & Overweight/obese & 13 & $3.5 \%$ & 1 & $7.1 \%$ & \\
\hline
\end{tabular}

\section{DISCUSSION}

In this study, the quality of sleep and its association was assessed with gender and body mass index in medical students of Karachi. Sleep quality is a subjective self-assessment, done by Pittsburgh Sleep Quality Index (PSQI) scale into good (scores <5) and poor sleep (scores $>5$ ). According to Pittsburgh Sleep Quality Index (PSQI) scale, $96.3 \%$ of the study participants had poor sleep (scores $>5$ ) which is similar to an Indonesian study (84.5\%) conducted by Alfian et al. ${ }^{7}$ In contrary to these results American and Nigerian studies reported $42 \%$ and $32.5 \%$ respectively. ${ }^{17,18}$ The high rate of poor sleep quality may be due to academic burden with exam afterwards, social lifestyle or social medias, alcohol/ caffeine intake, or central nervous system (CNS) stimulants intake, which prevent students from achieving sufficient sleep. ${ }^{6}$ It is closely associated with mood disturbances and risk factor for development of high arterial blood pressure or hypertension (HTN), high body mass index (overweight or obesity) and depression that affects the quality of life (QOL). ${ }^{7,9,10}$

The poor sleep quality affects the quality of life including physically and psychologically on the performances of students and exerts several physiological effects like worsening of glucose metabolism by impaired glucose tolerance and insulin sensitivity, increased sympathetic activity, elevated inflammation and imbalance in secretion of ghrelin and leptin, so subsequently affects the appetite and hunger. ${ }^{19}$ According to our results, gender based comparison of mean values of body mass index (BMI) and mean values of Pittsburgh Sleep Quality Index (PSQI) in males to females showed statistically significant $(p<0.05)$ differences. Similar type of results reported by a Chinese study. ${ }^{20} \mathrm{~A}$ significant association $(p<0.05)$ was observed in gender based comparison with sleep quality [good (scores $<5$ ) and poor sleep (scores >5)] which is supported by a Chinese study showing similar results. ${ }^{20}$ These gender based differences are due to structural differences or body difference or biological differences, circadian rhythm or circadian clock genes, respiratory control, sex hormones or sex steroid hormones, stress response, social behaviors that affects the quality of sleep in male and females. ${ }^{21,22}$ According to our results, there is no statistically significant ( $p>0.05$ ) association between different categories i-e underweight, normal weight, overweight and obesity with poor or good sleep quality in medical students. Multiple studies have reported similar results, which support our results. ${ }^{7,23,24}$ The poor sleep quality in students is responsible for changes in regulation of appetite by imbalance in secretion of ghrelin and leptin, so influences the calorie intake and intake of food choice. ${ }^{19,25}$

The study showed high rate of poor sleep(scores $>5$ ) quality pattern in medical students, so we have need to launch programs for students as to encourage healthy sleeping habits, healthy eating habits and physical activities, so that students can achieve their goals by a healthy performance in their medical education.

\section{CONCLUSION}

There was significant $(p<0.05)$ association of Sleep Quality with gender but no significant $(p>0.05)$ association of Sleep Quality with body 
mass index (BMI) in this study. Students which show poor sleep pattern ultimately leads to poor curricular and/or extracurricular performance in medical colleges. It is important to realize the need for timely recognition of sleep quality and Body mass index in students.

\section{Conflict of Interest}

This study has no conflict of interest to declare by any author.

Copyright(C) 18 June, 2020.

\section{REFERENCES}

1. Perla A. Vargas, melissaflores, BA, and elias robles. Sleep quality and body mass index in college students: The role of sleep disturbances. $\mathrm{J}$ am coll health. 2014; 62(8): 534-541.

2. Hall, J. 2016, Guyton and Hall textbook of medical physiology. 13th ed. Elsevier.

3. Shao M-F, Chou Y-C, Yeh M-Y, T zeng W-C. Sleep quality and quality of life in female shift-working nurses. $J$ Adv Nurs 2010; 66(7):1565-72.

4. Cappuccio F, D'Elia L, Strazzullo P, Miller M. Sleep duration and all-cause mortality: $A$ systematic review and meta-analysis of prospective studies. PubMed - NCBI [Internet]. Ncbi.nlm.nih.gov. 2018 [cited 22 October 2018]. Available from: https://www.ncbi.nlm. nih.gov/pubmed/20469800/.

5. Consensus Conference Panel, Watson NF, Badr MS, Belenky G, Bliwise DL, Buxton OM, Buysse D, Dinges DF, Gangwisch J, Grandner MA, Kushida C. Recommended amount of sleep for a healthy adult: a joint consensus statement of the American Academy of Sleep Medicine and Sleep Research Society. Journal of Clinical Sleep Medicine. 2015 Jun 15;11(6):591-2.

6. Killgore W. Effects of sleep deprivation on cognition. Progress in Brain Research. 2010; 105-129.

7. Sofa D. Alfian*, Henry Ng, Dika P. Destiani and Rizky Abdulah. Psychological distress induces poor sleep quality: A cross-sectional study of pharmacy students in Bandung City, Indonesia. The Open Public Health Journal, 2018, Volume 11. 369-375.

8. Buysse DJ. Sleep health: Can we define it? Does it matter? Sleep. 2014; 37(1):9-17.10.5665/sleep.3298 [PubMed: 24470692].
9. Mollayeva T, Thurairajah P, Burton K, Mollayeva S, Shapiro CM, Colantonio A. The Pittsburgh sleep quality index as a screening tool for sleep dysfunction in clinical and non-clinical samples: A systematic review and meta-analysis. Sleep medicine reviews. 2016 Feb 1;25:52-73.

10. Shittu R, Issa B, Olanrewaju G, et al. Association between subjective sleep quality, hypertension, depression and body mass index in a Nigerian family practice setting. J Sleep Disord Ther 2014; 3: 157. [http://dx.doi.org/10.4172/2167-0277.1000157].

11. Jun Wang1, Yan Chen1, Yuelong Jin1, Lijun Zhu1, Yingshui Yao1. Sleep quality is inversely related to body mass index among university students. Rev Assoc Med Bras 2019; 65(6):845-850.

12. Buboltz WC Jr, Brown F, Soper B. Sleep habits and patterns of college students: A Preliminary Study. J Am Coll Health. 2001; 50(3):131. [PubMed: 11765249].

13. Sing CY, Wong WS. Prevalence of insomnia and its psychosocial correlates among college students in Hong Kong. J Am Coll Health. 2010; 59(3):174-82. [PubMed: 21186447].

14. Buysse DJ, Reynolds CF III, Monk TH, Berman SR, Kupfer DJ. The pittsburgh sleep quality index: A new instrument for psychiatric practice and research. Psychiatry Res 1989; 28(2): 193-213. [http://dx.doi. org/10.1016/0165-1781(89)90047-4] [PMID: 2748771].

15. World Medical Association. World medical association declaration of Helsinki: Ethical principles for medical research involving human subjects. JAMA 2013; 310(20): 2191-4.

16. World health organization. WHO: Global database on body mass index n.d. Available from: http://apps. who.int/ bmi/index.jsp?introPage=intro_3.html.

17. Suen LKP, Hon KL, Tam WWS. Association between sleep behavior and sleep-related factors among university students in Hong Kong. Chronobiollnt 2008; 25(5): 760-75. [http://dx.doi. org/10.1080/07420520802397186] [PMID: 18780202].

18. James B, Omoaregba J, Igberase O. Prevalence and correlates of poor sleep quality among medical students at a Nigerian university. Ann Niger Med 2011; 5(1): 1-5. [http://dx.doi.org/10.4103/0331-3131.84218].

19. Lund HG, Reider BD, Whiting AB, Prichard JR. Sleep patterns and predictors of disturbed sleep in a large population of college students. J Adolesc Health 2010; 46(2): 124-32. [http://dx.doi.org/10.1016/j.jadohealth. 2009.06.016] [PMID: 20113918]. 
20. Tang, J. et al. Gender and regional differences in sleep quality and insomnia: A general populationbased study in Hunan Province of China. Sci. Rep. 2017; 7, 43690; doi: 10.1038/srep43690 ().

21. Mollayeva, T. et al. The Pittsburgh sleep quality index as a screening tool for sleep dysfunction in clinical and non-clinical samples: A systematic review and meta-analysis. Sleep medicine reviews. 2016; 25, 5273.

22. Mong, J. A. \& Cusmano, D. M. Sex differences in sleep: Impact of biological sex and sex steroids. Phil. Trans. R. Soc. B. 2016; 371, 20150110.
23. Lai PP, Say YH. Associated factors of sleep quality and behavior among students of two tertiary institutions in Northern Malaysia. Med J Malaysia 2013; 68(3): 195-203.

24. Eller T, Aluoja A, Vasar V, Veldi M. Symptoms of anxiety and depression in Estonian medical students with sleep problems. Depress Anxiety 2006; 23(4): 250-6. [http://dx.doi.org/10.1002/da.20166] [PMID: 16555263].

25. Rahe, C.; Czira, M.E.; Teismann, H.; Berger, K. Associations between poor sleep quality and different measures of obesity. Sleep Med. 2015, 16, 1225-1228.

\begin{tabular}{|c|c|c|c|}
\hline \multicolumn{4}{|c|}{ AUTHORSHIP AND CONTRIBUTION DECLARATION } \\
\hline Sr. \# & Author(s) Full Name & Contribution to the paper & Author(s) Signature \\
\hline 1 & Saleem Ullah Abro & $\begin{array}{l}\text { Concept, Write up, } \\
\text { Corresponding author. }\end{array}$ & \\
\hline 2 & Ghulnaz Khalid & Concept, Proof reading. & leem \\
\hline 3 & Qurratulain Saleem & Statistical analysis. & \\
\hline 4 & Maham Khan & Data collection literature review. & \\
\hline 5 & Sohail Ahmed & Data collection, Proof reading. & \\
\hline 6 & & Proof reading, Data collection. & a $M$. \\
\hline
\end{tabular}

